\title{
Aspects of the relationship between the processing of stimuli in the peripheral perceptual field and in the perceptual central field
}

\author{
Mihai Aniței ${ }^{1}$ \\ Cornel Laurențiu Mincu \\ Mihaela Chraif \\ Bucharest University
}

\begin{abstract}
As humans have limited information processing abilities and rely on three fallible mental functions: perception, attention and memory, the driving error is easy to appear. The purpose of this paper is to highlight the male/female differences in processing the perceptive information from the external stimuli in the peripheral visual field and to demonstrate that the mean of the estimate errors in evaluating the speed and distances in the central visual perceptual field is in inverse ratio to the reaction time value at the visual stimuli from the peripheral driving tasks simulation. Between the variables number of wrong reactions and number of omissions there has been obtained a relatively high negative correlation $(r=-0.728, p<0.001)$. The result has a strong implication in visual stimuli processing during driving tasks.
\end{abstract}

Key words: peripheral stimuli processing, gender differences, perceptual visual central field, central visual stimuli processing.

\section{Rezumat}

Datorită faptului că ființele umane au o capacitate limitată de procesare a informațiilor, iar în realizarea acestor procese se bazează pe funcții mentale imperfecte: percepția, atenția şi memoria, erorile pe parcursul condusului apar relativ uşor. Scopul acestei lucrări este de a sublinia diferențe dintre bărbați şi femei aşa cum apar în procesarea informației perceptive furnizată de stimulii externi din câmpul vizual periferic şi de a demonstra că media erorii estimate în evaluarea vitezei şi distanțelor în câmpul vizual perceptiv central este în raport invers cu valoarea timpului de reacție la stimulii vizuali din simulatorul de conducere. Între numărul reacțiilor greşite şi numărul omisiunilor $s$-a obținut o corelație negativă ridicată $(r=-0.728, p<0.001)$. Rezultatele au implicații puternice pentru procesarea stimulilor vizuali în timpul sarcinii de şofat.

Cuvinte cheie: procesarea stimulilor periferici, diferențe de gen, câmpul vizual perceptiv central, procesarea stimulilor vizuali centrali.

\section{Introduction}

In this article, we provide an overview of human information processing limitations and explain how they can interact with situational factors, to contribute to road accidents. This represents an approach to accident investigation because it draws on knowledge of basic human psychological processes, in particularly the cognitive processing of peripheral perception in driving.

\footnotetext{
${ }^{1}$ Adresa de corespondență: anitei_mihai@yahoo.com
}

Instead of looking at the driver from the outside, we try to understand the mental processes and how they interact with the environment. Furthermore, gender differences in the peripheral perceptive field represent an important objective concerning the driving of a vehicle, for this article's debate.

During driving a vehicle, people interact with a steady flow of informational stimuli. Most of the information represents visual input such as: other vehicles, pedestrians, the road, traffic signs and the passing scenery, and auditory input like talking on a cell phone, CD-player, radio, a conversation with the passengers, etc. As long as the visual information stimuli flow is 
low, there is enough mental resource to carry out all tasks simultaneously, and to execute the driving procedures safely. Whereas, a higher level of information may appear under the following circumstances: driving at a high speed, poor visibility, a car driver stopping his car ahead, the driver's capacity being lowered by age, drugs, alcohol or tiredness. Thus, the driver should only attend to a subset of the available information, which could be used to make decisions and to respond, and the rest of the information can be ignored.

\section{Driving and traffic accidents}

The drivers as human beings are able to see motion by registering the movement of an object image projected on the retina, the light-sensitive portion of the eye. When a driver looking ahead on the road is on a collision course with an object approaching from the side, there is no retinal image motion (Green, 2000). In his studies, Green $(2000,2001)$ revealed that if a vehicle driver is moving forward towards a collision course with a train while the train is in a leftward motion, three situations may occur: 1)The driver arrives before the train (in this case, the angle increases, and the retinal image moves further to the periphery); 2) The train arrives before the driver (in this case, the angle decreases, and the retinal image moves toward the fovea); 3)The driver and the train arrive at the same moment. The car and train movements cancel out, and the angle remains constant. There is no retinal image motion, so the speed is more difficult to judge accurately.

In order to better understand the driver behavior and the sources of driver distraction, researchers have attempted to develop integrated driver models that capture driver behavior in a computational manner (Aasman, 1995). These models provide insight into the sources of distraction by elucidating the processes by which a driver attends to the external environment, cognitively processes this information, and then reacts to the information stimuli and manipulates the environment. Thus, IT architectures could provide an opportunity to handle multitasking at the "software level" through new models implemented as production rules and at the "hardware level" through changes to the architecture's inner mechanisms.

The short-term memory (working memory) plays a very important role for the drivers in collecting information (visual, auditory, and knowledge stored in the permanent long-term memory) during interpreting the sensorial input and taking decisions. The working memory has two severe limits that often play a role in vehicle accidents: the information remains in the working memory for a short time, if it is not used or refreshed; older information may be flushed out at any time by some newer input (Smith, Fredrickson, Loftus, NoelenHoeksema, 2004). Since working memory records all sorts of information, stimuli received from CD-player, radio or cell phone, it can also be filled up and cause the ignorance of important stimuli from the environment (traffic signs, pedestrians, vehicles speeding).

The minimum contrast necessary to see an object in a given set of circumstances is affected by many factors. These can be divided into two classes, environmental and driver-related (Green, 1992).

The environmental class of factors is represented by: the size (size as in "visual angle", rather than inches or centimeters, which gives the size of the retinal image); distance (the closer it is, the more visible it becomes - it has a bigger visual angle); the visual field location (vision is best when objects are imaged in the fovea, the part of the eye with the highest resolution); shape (objects are easier to see when they are solid simple figures such as blobs, disks, rectangles, etc); duration (visibility increases with longer duration); Motion/Flicker (these can make an object more visible, the influence of motion on visibility depends on size and velocity); masking and camouflage (objects are also harder to be seen when the background has shapes or textures, and easiest when the background isn't changing); glare (when a very bright light, one that is far above the current adaptation level, suddenly appears, it reduces visibility); weather (rain, snow and fog all decrease visibility).

The drivers' class factors are: the age (contrast sensitivity decreases with age); adaptation status (visibility is best when the driver is adapted to the same lighting as the background); optical status (visibility decreases when the driver is not wearing optical correction for the viewing distance); arousal level (alcohol, drugs and other medication can affect arousal level); uncertainty (visibility is the best when he knows when and where the object will be located, any spatial or temporal uncertainty raises threshold); expectation 
(viewers can be greatly affected by their expectations).

Research shows that some of the objects' properties make them "pop out" and automatically attract attention ((Wang, Cavanagh \& Green 1994). Green (1992) highlighted that objects are more likely to popout and be conspicuous if they: are large, have high brightness contrast, move or flicker rapidly or suddenly appear, are meaningful and if they are expected.

This automatic attraction of attention is important in driving. Research shows that drivers spend half or more of their time looking directly ahead to the point where the road meets the horizon (Green 1992).

Usually by "driving performance", the psychologists refer to the driver's knowledge, skill, and perceptual and cognitive abilities. This vision is distinct from the driver's vision as the individual driving a car through the traffic towards the destination.

The driving task represents a closedloop compensatory feedback control process, meaning that the driver makes control inputs (to the steering wheel, brakes, and accelerator pedal), receives feedback by monitoring the consequences of the inputs, and in response to these consequences, makes additional inputs (Wang, Cavanagh \& Green 1994). Broken up into fine details, the driving task is very complex, involving the simultaneous control of lateral and longitudinal position through the use of the steering wheel, accelerator, and brakes, together with many pattern recognition and other higher level cognitive skills, such as estimating future situations based upon the present information. While the basic skills required for driving a vehicle are usually learned quickly and easily, some of the higher-level skills that affect safety can be acquired only after many years of experience.

Numerous studies (HakamiesBlomqvist, 2002, Green 1992, 2000, 2001) over many decades have failed to show any clear relationship between the most basic measure of visual performance, visual acuity, and crash risk. Crash rates decline to a minimum at about 45 years of age, by the time which the visual acuity and contrast sensitivity have already begun to decrease, such as other visual capabilities relevant to driving, such as the ability to withstand glare (HakamiesBlomqvist, 2002).

Changes in the higher-level visual characteristics, in particular the useful field of view, the area from which useful visual information can be extracted in a single glance, have been shown to be related to the crash involvement risk. Pattern recognition skills are essential to the driving task. From a stimuli-rich visual environment, the driver must select the information that is relevant from all the information that is not relevant in any way.

During driving, each time a driver consults the speedometer, the perceived speed can be compared to the actual speed. Those operations are additionally motivated by the need to respect speed limits (traffic rules). The repetitive practice, with feedback, of this task might suggest that drivers can become very good at estimating their speed.

The main cue for speed is related to peripheral vision. When the peripheral vision is eliminated, leaving only the central field of view to determine speed, estimates become inaccurate because the vehicle's forward movement produces little change at the edge of the visual field.

The reaction times play an important role in safely driving. Reaction times are influenced by many factors, but, for driving, the two most important are first: the number of stimuli and possible responses and second: expectancy. Reaction times in driving involve identifying a variety of events in a complex environment, so it is not surprising that reaction times bear little resemblance to the minimum possible in laboratory tests.

Furthermore, age or body damages or deficiencies can impact the driving ability. Murray-Leslie (1991) highlighted in research that arthritic drivers suffering of chronic joint pains or deformed joints have problems with driving. Many studies and researches have shown that perceptual and psychological mechanisms exist, in order to compensate for the functional losses of auditory or visual paths. Looms (1998), Klatzky (1990) and Manton (1989) conducted different experiments investigating the visual and sound distance perception under full-cue conditions and reduced-cue conditions. After examining navigation ability in the absence of the sight, Klatzky and collaborators (1990) concluded that cognitive motor coordination performance was quite accurate for simple paths. Manton (1989) indicated that the acceptance of age-related functional losses can negatively impact actual abilities and recommended a more active approach to preserving functional abilities in order to be 
adopted at later ages by reinforcing a positive self-image to the elderly people.

Considering the technological explosion within the last decade, the human factor can easily compensate the physical and physiological deficiencies using vehicle design adaptation while driving. Many changes could be made to standard vehicles including: seating, seat and door dimensions, handles, knobs, anti-glare adaptation, steering wheels, and mechanical driving control. Thus, the antiglare adaptation provides non-glare panels and day/night rearview and side mirrors. Haigh (1993), based on the ideas of Pirkl and Babic (1988), proposed design guidelines to improve the visibility of the vehicle control panels and dials: to ensure an adequate light level on text and controls; to select appropriate color, size and chromatic intensity for the symbols; to eliminate the irrelevant information and considering the advanced technologies many others improvements could be made to aid disabled drivers during driving: auditory information systems, visual enhancement devices, in-vehicle information, support systems (developed to address decline in perceptual, cognitive and physical performance) and emergency aid networks.

\section{Perceptual processing of the stimuli in the peripheral and central visual fields in driving}

A person, interacting with others, watches the others' eyes for signs of attention and understanding, for clues and indications.

Brebner and Welford (1980) reviewed literature that shows that visual stimuli perceived by different portions of the eye produce different reaction times. The fastest reaction time comes when a stimulus is seen by the cones (when the person is looking right at the stimulus). If the stimulus is picked up by rods (around the edge of the eye), the reaction is slower. Ando, Kida, and Oda (2002, 2004) found that practicing a visual stimulus in the central vision shortened the reaction time to a stimulus in peripheral vision, and vice versa.

Pylyshyn (1998) suggested that many of the apparent spatial and directional properties of images could derive from real space, providing a mechanism for associating features or objects in images with corresponding objects in real space. This view has been developed in connection with a theory of visual indexes, which provides a mechanism for preconception links to objects in the world (Pylyshyn, 2000, 2001a).

Some of the cortical activity observed during both motor performance and the mental transformation of visual images, may reflect the fact that posterior parietal cortex area compute higher-level functions required for extrapolating trajectories, for tracking, for planning, and for visual-motor coordination (Anderson, Snyder, Bradley, \& Xing, 1997).

The visual field is the area of extent of physical space visible to an eye in a given position, measured by plotting the ability of the eye to discern motion, form or color at differing angles from the eye (Anderson \& Holliday, 1995). There are significant individual differences in the peripheral threshold for motion, and there is more variability at the extreme points of the periphery (at a greater peripheral angle). A peripheral vision limitation occasionally represents a problem with the particularly complex junctions where the number of directions from which traffic can potentially approach is more than normal. Peripheral vision is relied upon to a greater extent in these situations and the safety of cyclists, motorcyclists and pedestrians at junctions often depends upon the drivers peripheral vision, as the focus of his or her attention will often be on other motor vehicles in the main stream of traffic. Levi, Klein and Hariharan (2002) highlighted in their research that peripheral crowding is not scale invariant nor is it attributable to simple contrast masking. Rather, the results suggested that inhibitory spatial interactions in peripheral crowding extend over larger distances than in the fovea for targets of the same size. In the peripheral vision, the critical distance for crowding is approximately 0.1 times the target eccentricity. Observers can easily detect the features that compose the authors' targets (Gabor patches) under conditions of intense crowding (Levi, Klein, Hariharan, 2002).

Loke and Song (1991) reported faster detection times for peripheral, visual stimuli for deaf than for hearing individuals. Thus, the little available evidence raises the possibility that peripheral processing is modified after early deafness. In his study, Gilden, Blake and Hurst (1995) used visual motor adaptation to study how the visual system is involved in the creation of mental images. This study was very important considering that the motor adaptation is retinotopic and because of this, appears in the primary visual system. Thus, when a region of the visual field receives an 
extended motor stimulation, an object in that region is seen as moving in the opposite way from the inductive movement (the waterfall illusion) and a mobile object is seen as if it moved slower. The researchers have conceived their study with the intention of demonstrating that the movement of an imaginary object is affected by the ulterior effect of the moving field. Thus, they discovered that when the point was imagined as moving in the same direction as the inductive moving field (contrary to the ulterior moving effect), this appears to have slowed down (it took it a long time to reach the other part of the region). Moreover, the point appeared to gain speed and reached the other side in less time when the point was imagined to move in the opposite direction from the moving inductive field (in the same direction with the ulterior moving effect). The conclusion was that in the visual moving adaptation, the moving seems to slow down in spite of the direction in which the inductive moving field is moving, probably because all the receptors sensitive to movement have been made tired.

In another research, Pylyshyn and Cohen (1999) asked their subjects to extrapolate a small square's movement, which disappeared behind an apparently opaque surface. The subjects were asked to imagine the slight movement of the square in a dark room. At a certain unexpected time, the square would appear again, as if from a crack of the opaque surface, then disappear again through another space, and the subjects would then be told to indicate if the square reappeared before or after their imagined square reached the space. This task took place in several different conditions. In one of them, the placement of the "space" where the square was due to appear and disappear was unknown (the spaces were invisible). Both the discoveries confirmed the idea that the subjects, when reporting "the image of the square's slow movement", actually select places to calculate the time until contact and they barely think that the imaginary moving square is at the designated places at the designated time. According to this opinion, the subjects think that "here is now" repeatedly for the different moving objects and synchronized with the arrival times calculated.

Bavelier and collaborators (2000) used the functional magnetic resonance imaging (fMRI) technique to test the hypothesis that allocating attention to the peripheral visual space is specifically enhanced after auditory deprivation. They used structural equation modeling to characterize how this modulation arises within the visual pathway. The participants included hearing and deaf individuals who viewed alternating blocks of static dots and flowing fields of moving dots. Visual attention was engaged by requiring participants to monitor the display for luminance changes. Changes in visual attention with eccentricity were tested by contrasting runs in which subjects had to monitor luminance changes in the periphery with those in which subjects had to monitor the luminance changes in the center of the visual field. Taken together, these results demonstrate specific changes in the organization of the motion pathway in congenitally deaf individuals. In all viewing conditions, deaf individuals, unlike hearing subjects, displayed left lateralized MT/MST activation. When attending to the periphery, deaf individuals displayed a larger recruitment of the motion pathway than hearing individuals, whereas no population differences were noted when attending to the center. This result implies that peripheral space representation is more dependent on, and modifiable by, early auditory deprivation than is the representation of central visual space.

Other studies and research were focused on highlighting if crowding in foveal and peripheral vision appears to differ in two important ways (Levi, Klein \& Carney, 2000). This view is consistent with the finding that crowding in foveal and peripheral vision is qualitatively different (Hess, Dakin, Kapoor, \& Tewfik, 2000).

\section{The perceptual processing: Bottom- up and top-down approaches}

The top-down effects play a crucial role in processing sensorial information. Therefore, several effects have been demonstrated by many anatomical and psychophysical studies: priming (Stins \& van Leeuwen, 1993), stimulus context (Bar \& Ulma, 1996), expectancy (Downing, 1988) and object centered attention (Lavie \& Driver, 1996; Driver \& Spence, 1998). All these results suggested that the processing and subjective perception of external stimuli to a passive bottom-up process depending on the actual stimulus are also determined by internal states like expectation, attention or past experience. Siegel et al. (2000) proposed a model describing the interaction of bottom-up and 
top-down signals on a cellular level, leading to experimental predictions. The results of the experimental research evidenced that the model demonstrates how computational properties of somato-dendritic interactions could play an important role in the integration of bottom-up and top-down processing. Based on further research and studies revealing that in the hierarchy of areas in the visual system, neurons have increasingly complex receptive fields which establish an elementary form of "knowledge" (Siegel et al., 2000) even if the system receives no additional external topdown signals, the reciprocal connectivity leads to top-down signals based on the "knowledge" of the higher areas.

\section{The gender influences in stimuli processing in the peripheral perceptual field}

There is considerable controversy over both the existence and the magnitude of gender differences in special abilities. Thus, many studies and research have found no gender differences (Caplan, MacPearson \& Tobin, 1985), while other studies have revealed gender differences favoring males versus female that have persisted across development (Linn, Petersen \& Sorby 1998).

There are several theories that attempt to explain gender differences in spatial abilities using both biologically based and nonbiologically based perspectives. Eals and Silverman (1994) presented the HunterGatherer theory of spatial gender differences based on the result of human-evolution. According to this explanation, males were hunters and therefore, they excelled in tasks that used spatial abilities and females were gatherers and they excelled in tasks related to foraging, such as peripheral perception.

In order to support the biologically based explanation, there are research and studies showing different brain activation for males and females. Aside from external anatomical and primary and secondary sexual differences, scientists know also that there are many other subtle differences in the way the brains from men and women process language, information, emotion and cognition. One of the most interesting differences appear in the way human male and female estimate time, judge the speed of objects, carry out mental mathematical calculations, direct themselves in space and visualize objects in 3D. In all these tasks, human male and female are strikingly different, as they also are in the way their brains process language (Smith et all, 2004). On the other hand, females are better than males in human relations, recognizing emotional overtones in others and in language, emotional and artistic expressiveness, aesthetic appreciation, verbal language and carrying out detailed and preplanned tasks (Kimura, 1999).

\section{Left hemisphere versus right hemisphere in peripheral and central visual field stimuli processing during driving tasks}

The hemispheres of the cerebrum are specialized for different tasks. The left hemisphere is regarded as the verbal and logical brain, and the right hemisphere is thought to govern creativity and spatial relations, among other things. Also, the right hemisphere controls the left hand, and the left hemisphere controls the right hand. This has made researchers think that the left hand should be faster at reaction times involving spatial relations (such as pointing at a target). The results of Bartélémy and Boulinquez $(2001,2002)$ all supported this idea. Dane and Erzurumluoglu (2003) found that in handball players, the left-handed people were faster than right-handed people when the test involved the left hand, but there was no difference between the reaction times of right handers and lefthanders when using the right hand. Finally, although right-handed male handball players had faster reaction times than right-handed women, there was no such gender difference between left-handed men and women. The authors concluded that lefthanded people have an inherent reaction time advantage. Bryden (2002), using right-handed people only, found that the difficulty of the task did not affect the reaction time difference between the left and right hands.

Analyzing Central versus Peripheral Vision, Brebner and Welford (1980) cite literature that shows that visual stimuli perceived by different portions of the eye produce different reaction times. According to these findings, the fastest reaction time comes when a stimulus is seen by the cones (when the subject is looking right at the stimulus) and when the stimulus is picked up by rods (around the edge of the eye), the reaction is slower. Ando et al. (2002) found that practice on a visual stimulus in central vision shortened the 
reaction time to a stimulus in the peripheral vision, and vice versa.

In driving, the space-time coordination is very important from a practical perspective. A very important element is the ability to estimate the speed and distance in a correct manner, which is influenced by several variables: visual, acoustic, kinesthetic and emotional according to the width and the length of the movement field, the size of the moving object, the environment structure, the approximate direction to the observer, the light within the moving field, etc (Barthelemy \& Boulinguez 2001, 2002).

\section{Objectives}

The research objectives are the followings:

- Outlining the differences between genders in processing the perceptive information from the external stimuli in the peripheral visual field;

- Studying the association between the peripheral visual field stimuli processing and the central visual field processing stimuli during simulated driving tasks;

\section{Hypothesis}

1. The gender differences influence the performances of stimuli processing tasks in the perceptive peripheral field in different ways. We assume that male subjects will have better performances than female subjects, considering the reaction time in responding to the stimuli and the number of stimuli detected at the peripheral perception task.

2. The mean of the estimate errors in appreciation of the speed and distances will be in inverse ratio to the reaction time value at the visual stimuli from the peripheral driving tasks simulation.

\section{Methodology}

\section{Participants}

The participants were 164 students at the Faculty of Electronics, Automatics, Psychology and Educational Science (84 females and 80 males), the age between 21 and 27 years old $(m=24 S D=3)$. The first step of selection used the criteria of selection: "driving license for 1 year minimum and 5 years maximum". Using this criterion, a group of 463 subjects were able to participate to the research. We randomly selected 164 participants (84 female and 80 male), from the subjects having a driver's license. These subjects represented the group for testing the first hypothesis regarding the gender differences in visual peripheral field processing stimuli.

A second group of subjects (43 subjects, males and females) was randomly selected from the first group of 164 participants in order to test the second hypothesis of the research.

\section{Experimental designs}

The experimental design for the first hypothesis: between subjects design, two groups male (80) and females (84), in one experimental condition (processing visual stimuli in peripheral field) during simulated driving tasks.

The experimental design for testing the second hypothesis: within subjects design, one group (43 subjects) in two visual stimuli processing simulated driving situations. The first simulated driving situation was the peripheral visual field processing stimuli task and the second simulated driving situation was the central visual field processing stimuli task.

\section{Instruments}

1. The peripheral perception test (Schuhfried, 1992) is destined to evaluate one's abilities to perceive and process the visual peripheral information, and mostly on the rapid perception of the stimuli that enter the visual field through the lateral sides.

The test can be administered as a unique test or as a background test simultaneously with a foreground test. In both the testing versions, the subject's visual attention is centered on the monitor, either on the globe appearing in the center of the screen, or on the foreground test. The test is presented with a special testing machine, incorporating a peripheral exposure consisting in light-emitting diodes that are arranged on horizontal and vertical and allow the luminous stimuli to move from the edges to the center of the visual field. The foreground test or the globe is presented on the machine's screen.

The DEST test (Schuhfried, 1992) studies the subject's ability to estimate the speed and distance, displaying a small rectangle on the monitor that moves with a constant speed from the left side to the right, in a horizontal manner and represent a driving 
simulation task regarding the central visual field stimuli processing.

The central role of the DEST test is played by the white spot (small rectangle) which disappears after a certain distance behind an invisible barrier. The subject has to push a button when he thinks the rectangle would reach the edge of the barrier, which is signaled with a vertical line at the edge of the screen.

\section{Procedure}

At the beginning of the Peripheral Perceptual Test, the examiner verbally informed the subjects in a different manner, depending on the chosen test: a) for PPT as a unique test: "On the central screen of the machine you will see a globe that you have to gaze at during the whole test. During this time, the luminous stimulus will move from the edge of the machine to the center. Once you see this type of light stimulus, push the yellow pedal” or b) for PPT as a background test „The text instructions appeared on the middle screen of the machine. Go through the instructions and once you understood everything you can start the test. From the moment the test has begun and while you work with it, a light stimulus will move from time to time from the edge of the screen to the center.
Once you are able to see such luminous stimuli with the corner of your eye, press the yellow pedal."

The participants are informed that they have to focus on a white spot (small rectangle) which disappears after a certain distance behind an invisible barrier. The participants have to push a button when he thinks the rectangle would reach the edge of the barrier, which is signaled with a vertical line at the edge of the screen.

Following the procedures carrying out, the results from both tests were computed using t- test for independent groups (male/female) in order to confirm the first hypothesis and the Pearson correlation in order to confirm the second hypothesis.

\section{Results and discussion}

Considering the first experimental design (for the first hypothesis): between subjects design (male and female), in one experimental condition (processing visual stimuli in peripheral field) during simulated driving tasks it was applied t-test for independent groups. The results can be observed in table 1.

Table 1. The mean, Std. deviation, Std. Error mean and statistical significance of gender differences

\begin{tabular}{|c|c|c|c|c|c|c|}
\hline $\begin{array}{l}\text { The task } \\
\text { response }\end{array}$ & Gender & $\mathrm{N}$ & Mean & $\begin{array}{c}\text { Std. } \\
\text { Deviation } \\
\end{array}$ & $\mathrm{t}$ & $p$-value \\
\hline \multirow[t]{2}{*}{ Correct } & Female & 84 & 47.13 & 4.41 & -3.42 & 0.001 \\
\hline & Male & 80 & 48.99 & 2.15 & & \\
\hline \multirow[t]{2}{*}{ Wrong } & Female & 84 & 5.78 & 6.78 & 3.10 & 0.002 \\
\hline & Male & 80 & 3.18 & 3.39 & & \\
\hline \multirow[t]{2}{*}{ Omitted } & Female & 84 & 2.87 & 4.41 & 3.38 & 0.001 \\
\hline & Male & 80 & 1.02 & 2.16 & & \\
\hline \multirow{2}{*}{$\begin{array}{l}\text { Left average } \\
\text { reaction time }\end{array}$} & Female & 84 & 1.97 & 0.45 & 6.05 & 0.001 \\
\hline & Male & 80 & 1.54 & 0.46 & & \\
\hline \multirow{2}{*}{$\begin{array}{l}\text { Right average } \\
\text { reaction time }\end{array}$} & Female & 84 & 2.05 & 0.44 & 6.37 & 0.001 \\
\hline & Male & 80 & 1.60 & 0.48 & & \\
\hline \multirow{2}{*}{$\begin{array}{l}\text { Total average } \\
\text { reaction time }\end{array}$} & Female & 84 & 2.01 & 0.43 & 6.30 & 0.001 \\
\hline & Male & 80 & 1.57 & 0.46 & & \\
\hline \multirow[t]{2}{*}{ Left std. dev. } & Female & 84 & 0.73 & 0.21 & 5.94 & 0.001 \\
\hline & Male & 80 & 0.54 & 0.18 & & \\
\hline \multirow[t]{2}{*}{ Right std. dev. } & Female & 84 & 0.76 & 0.20 & 6.41 & 0.001 \\
\hline & Male & 80 & 0.56 & 0.19 & & \\
\hline \multirow[t]{2}{*}{ Total std. dev. } & Female & 84 & 0.75 & 0.19 & 6.83 & 0.0001 \\
\hline & Male & 80 & 0.56 & 0.17 & & \\
\hline
\end{tabular}


Following the data from the table 1 we have made a few findings:

Women, as well as men have obtained a smaller medium reaction time for the stimuli entering the visual field from the left side, comparative to the ones coming from the right side.

The processing of the stimuli entering the visual field is done differently according to gender. Thus, the perceptive-peripheral processing occurs faster at men $(m=1.57)$, then it does at women $(m=2.01)$, regarding the stimuli entering the visual field from the right side as well as the ones entering from the left side;

The value of the $t$ test for independent samples $(t=6.30, p<0.001)$ indicates the fact that the difference is significant;

Right average reaction time $($ female $/$ male $)=2.05 / 1.60, \quad$ statistically significant results $(t=6.366, p<0.001)$ and for Left average reaction time (female/male) = $1.97 / 1.54$, statistically significance results $(t=$ 6.053, $\mathrm{p}<0.001$ ).

Giving an interpretation to the results, we concluded that: "The gender differences influence the performances of the processing stimuli tasks in the perceptive peripheral field in a different way" had been confirmed.
Furthermore, the assumption "the male subjects will have better performances than female subjects, considering the time reaction response to the stimuli and the number of stimuli detected at the peripheral perception task." it has been statistically confirmed by the obtained results.

Considering the experimental design for testing the second hypothesis: within subjects design, one group (43 subjects) in two visual stimuli processing simulated driving situations; we used for analyzing the results the t-test for paired groups and for the correlative study the Bravais-Pearson linear correlation coefficient. The first simulated driving task situation was the peripheral visual field processing stimuli task and the second simulated driving situation was the central visual field processing stimuli task.

\section{The peripheral perception tests' results in processing visual stimuli during a driving task simulation.}

The shapes of the both empirical distributions are quite normal (figure 1) thus, we applied the parametric statistic for significance tests.

Table 2. Central tendency and standard deviation values for the PP test indicators $(N=43)$

\begin{tabular}{lll}
\hline & Mean & Standard Deviation \\
\hline \hline Left average reaction time & 1.87 & 0.487 \\
\hline Right average reaction time & 1.99 & 0.511 \\
\hline Total average reaction time & 1.93 & 0.492 \\
\hline Left standard deviation & 0.66 & 0.194 \\
\hline Right standard deviation & 0.68 & 0.200 \\
\hline Total standard deviation & 0.69 & 0.168 \\
\hline
\end{tabular}
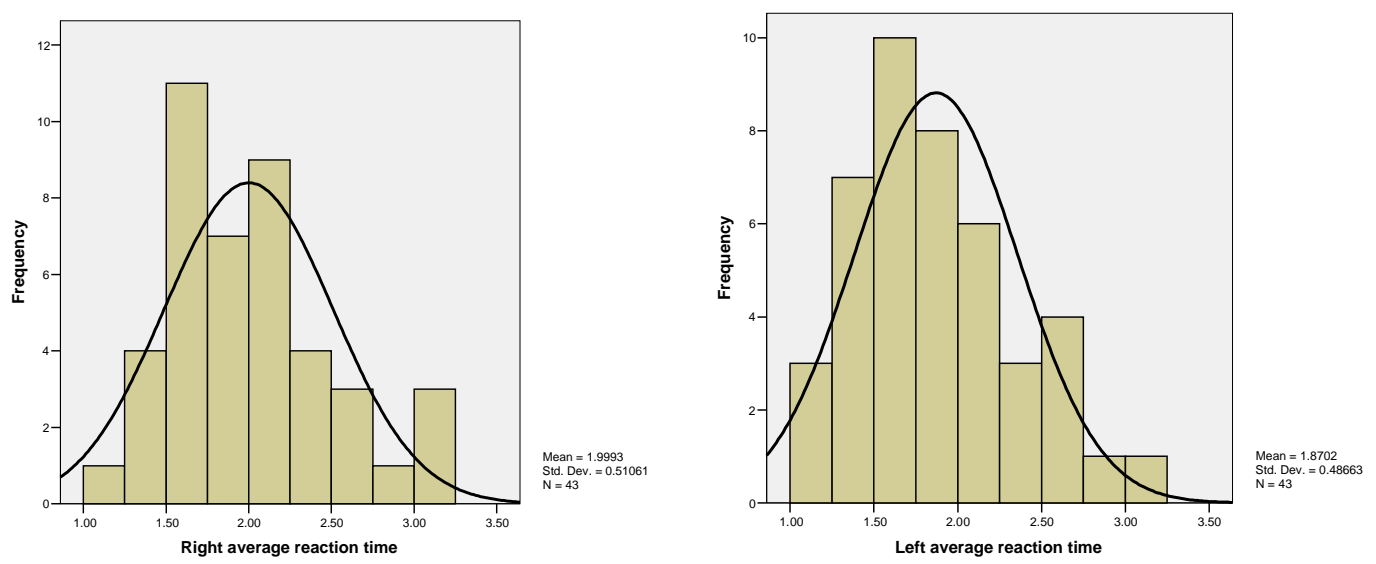

Figure 1 The histograms of left and right average reaction time 
Considering the dependent variable "Left average reaction time" and "Right average reaction time", a t-test for paired groups tested the statistically significant differences. The results of $\mathrm{t}$-test $(\mathrm{t}=4,9$, $p>0.01)$ confirm no significant difference between the two variables.

The peripheral processing reflected by the subjects' reactivity to imperative stimuli is differentiated in connection to the area in which the stimuli are being administered.

The subjects' reactivity for the stimuli entering the visual field from the left side is significantly $(p<0.05)$ better $(m=1.87)$ than the ones entering from the right side $(m=1.99)$ (table 2).

\section{The DEST Tests' results for the appreciation of speed and distances in central visual field driving simulation tasks}

Considering DEST test as a visual task driving simulation for the central field stimuli processing, the descriptive statistics of the dates obtained from the subjects' performed tasks can be seen in table 3 .

Table 3. Central tendency and standard deviation for the DEST test indicators $(\mathrm{N}=43$ )

\begin{tabular}{ccc}
\hline & Mean & $\begin{array}{c}\text { Standard } \\
\text { Deviation }\end{array}$ \\
\hline \hline $\begin{array}{c}\text { Number of Correct } \\
\text { Estimations }\end{array}$ & 2.26 & 21.39 \\
\hline $\begin{array}{c}\text { Number of } \\
\text { underestimations }\end{array}$ & 16.02 & 11.03 \\
\hline $\begin{array}{c}\text { The tendency of } \\
\text { estimations }\end{array}$ & -4.86 & 20.98 \\
\hline $\begin{array}{c}\text { The mean of } \\
\text { estimation error }\end{array}$ & 30.01 & 12.72 \\
\hline
\end{tabular}

Measures of central tendency and variability are basic descriptive statistics that summarize the distribution of the variables. In order to test the second hypothesis which assumes that the mean of the estimate errors in evaluating the speed and distances in central visual perceptual field will be in inverse ratio to the time reaction value at the visual stimuli from the peripheral driving tasks simulation, the Bravais-Pearson linear correlation coefficient was used.

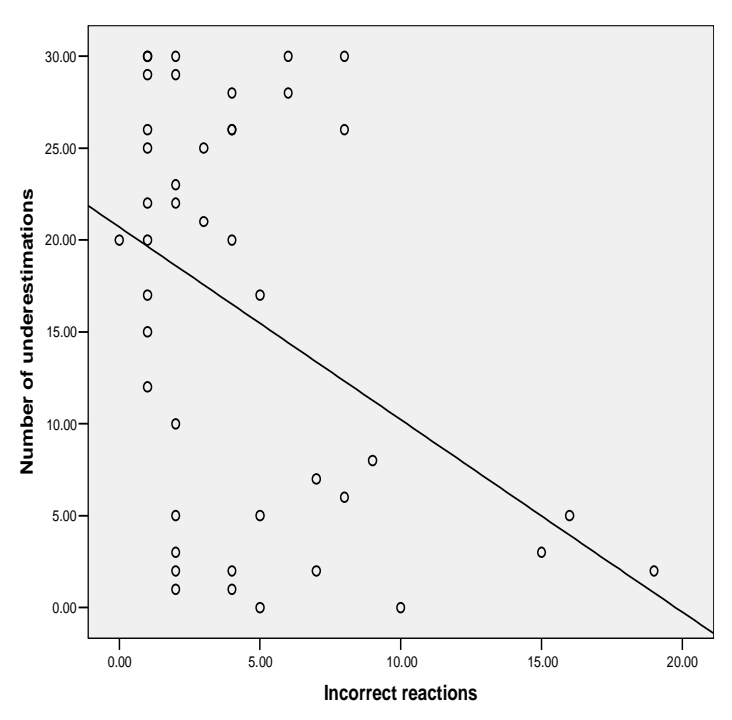

Figure 2 The relationship between the "number of underestimations" (DEST test) and the "number of wrong reactions" (Peripheral perception), $\mathrm{N}=43$

The graphic representation of the bivariate distribution (figure 2) indicates a medium negative correlation. The correlation coefficient's value $(r=-0.40, \quad p<0,05)$ indicates the fact that in the peripheral field (left and right), the more wrong reactions to the peripheral stimuli in driving simulation tasks, the more the number of speed underestimates tends to be reduced providing better stimuli processing in the central visual perceptive field.

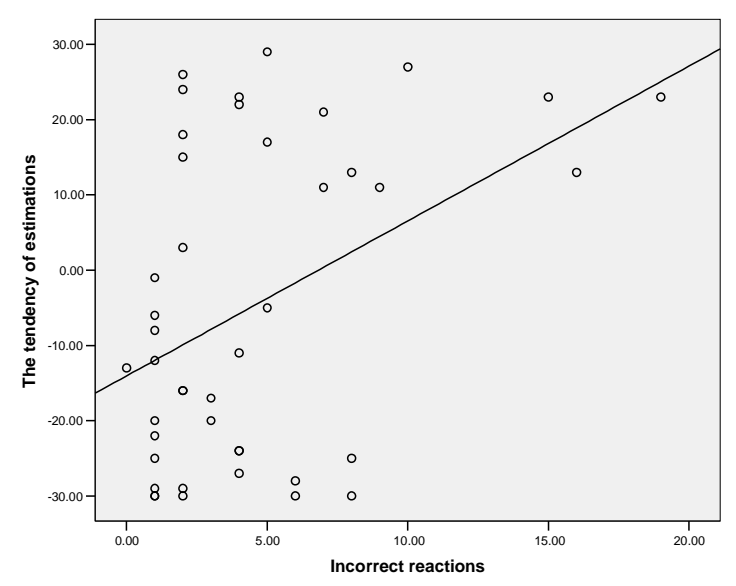

Figure 3 The relationship between the "estimation tendency" variable (DEST test) and the "number of incorrect reactions" (peripheral perception), $\mathrm{N}=43$ 
Considering the estimation tendency (in the speed and distance estimation test represents the absolute difference between the number of overestimation and underestimations) and the number of incorrect reaction to the peripheral stimuli (peripheral perception test), the correlation coefficient Pearson-Bravais $(r=0.42, \quad p<0.005), \quad(N=43)$ does not indicates a strong correlation between the two variables. The graphic representation (Figure 3 ) of the scatter plot indicates the fact that the more errors in the peripheral processing (between 0 and 10), there is a tendency for a correct estimation of the cinematic parameters on the basis of the descending processing. Still, after passing a certain number of peripheral errors (between 10 and 20), we can notice a significant increase of the overestimating tendency for the stimuli's moving speed in the central perceptive field. In this situation, the error is present at the periphery and also in the processing made by the central perceptive field. This fact can be caused by the field difference in which the perception is being made, as well as other motivational, temperamental etc. factors (there is not a homogenous distribution of the scores).

Between the variables number of wrong reactions and number of omissions there has been obtained a relatively high negative correlation $(r=-0.728, \quad p<0.001)$, $(\mathrm{N}=43)$. It has to be said that for this correlation, only the dates from the subjects that omitted reactions in the speed estimation test have been used.

\section{Conclusions}

Driving represents a multitasking activity that requires drivers to focus their attention towards environmental stimuli either in peripheral visual field or in the central visual field. The driving accidents are explained by the cognitive processing of the peripheral and central visual field stimuli in particular and by the human psychological processes in general as the reviewed research and studies were presented in this paper.

Analyzing the results the mean of the estimate errors in appreciation of speed and distances has been confirmed as being in inverse ratio to the time reaction value at the visual stimuli from the peripheral driving tasks simulation (between the variables number of wrong reactions and number of omissions it has been obtained a relatively high negative correlation $(r=-0.728, p<0.001),(N=43))$.

Testing the influence of subjects' gender on the peripheral visual stimuli processing, statistically significant difference has been obtained using t-test for independent groups (table 1).

Based on previous studies (Anitei, Buzea, Chraif 2007 Anitei, Chraif 2007) the present study highlights the importance of the reaction time in peripheral processing visual stimuli during driving task. During driving simulation tasks were being carried out, the subjects interact with the simulated environment (external stimuli in peripheral and central field as light stimuli) throw pedals and buttons producing behavioral protocols similar to those of the subjects during driving.

Nevertheless, we demonstrated in this study that increasing the errors in peripheral visual field correlate in inverse ratio with decreasing the speed and distances appreciation in the central visual field during driving simulation tasks. Furthermore, obtaining the Pearson negative correlation, it has been confirmed that the mean of the estimate errors in evaluating the speed and distances in central visual field are in inverse ratio to the time reaction value at the peripheral visual stimuli driving simulation tasks.

Thus the results obtained could help the subjects learn to focus their attention on the peripheral/central visual field stimuli that need attention during driving tasks. Also, they can exercise responses to both stimulations (from external stimuli) in central and peripheral visual fields preventing the traffic accidents based on stimuli detection in peripheral and central visual field.

\section{References}

Aasman, J. (1995). Modeling driver behavior in Soar. Leidschendam, the Netherlands: KPN Research.

Anderson, S.J., \& Holliday, I.E. (1995). Night driving: effects of glare from vehicle headlights on motion perception. Ophthalmic and Physiological Optics, 15, 545-551.

Anderson, R. A., Snyder, L. H., Bradley, D. C., \& Xing, J. (1997). Multimodal representation of space in the posterior parietal cortex and its use in planning movements. Annual Review of Neuroscience, 29, 303-330.

Ando, S., Kida, N., \& Oda., S. (2002). Practice effects on reaction time for peripheral and 
central visual fields. Perceptual and Motor Skills, 95, 3, 747-752.

Ando, S., Kida, N., \& Oda., S. (2004). Retention of practice effects on simple reaction time for peripheral and central visual fields. Perceptual and Motor Skills, 98, 3, 897-900.

Aniței, M., Buzea, L. \& Chraif P.M. (2007). Correlative study between the motor reactivity and the speed reaction and processing distances in vehicle driving simulation tasks, Centenary of Psychology at the University of Bucharest, part.2, 519-528.

Aniței, M., \& Chraif P. M. (2007). The influence of Caffeine Addiction in Speed and Distances Appreciation during driving a Vehicle, Centenary of Psychology at the University of Bucharest, part.1, 257-265.

Bar, M., \& Ullman, S. (1996). Spatial context in recognition. Perception, 25, 343-352.

Barthélémy, S., \& Boulinguez, P. (2001). Manual reaction time asymmetries in human subjects: the role of movement planning and attention. Neuroscience Letters, 315, 1, 4144.

Barthélémy, S., \& Boulinguez, P. (2002). Orienting visuospatial attention generates manual reaction time asymmetries in target detection and pointing. Behavioral Brain Research 133, 1, 109-116.

Bavelier, D., Tomann, A., Hutton, C., Mitchell, T., Corina, D., Liu, G., \& Neville, H. (2000). Visual Attention to the Periphery Is Enhanced in Congenitally Deaf Individuals, The Journal of Neuroscience, 20, 1-6.

Brebner, J.T., \& Welford, A.T. (1980). Introduction: an historical background sketch. Reaction Times. New York: Academic Press, 1-23.

Bryden, P. (2002). Pushing the limits of task difficulty for the right and left hands in manual aiming. Brain and Cognition, 48, 2-3, 287291.

Caplan, P.J., MacPherson, G.M., \& Tobin, P. (1985). Do sex-related differences in spatial abilities exist? A multilevel critique with new data. American Psychologist, 40, 786-799.

Dane, S. \& Erzurumluoglu, A. (2003). Sex and handedness differences in eye-hand visual reaction times in handball players. International Journal of Neuroscience 113, 7, 923-929.

Downing, C.J. (1988). Expectancy and visual-spatial attention: Effects on perceptual quality. Journal of Experimental Psychology. Human, Perception, Performances. 14, 188-202.

Driver, J., \& Spence, C. (1998). Cross-modal links in spatial attention. Philosophical Transactions
Royal Society London BilogicalSciences, 353, 1319-1331.

Eals, M., \& Silverman, I. (1994). The huntergatherer theory of spatial sex differences: Proximate factors mediating the female advantage in recall of object arrays. Ethology \& Sociobiology, 15, 95-105.

Gilden, D. L., Blake, R., \& Hurst, G. (1995). Neural adaptation of imaginary visual motion. Cognitive Psychology, 28, 1-16.

Green, M. (1992). Visual Search: detection, identification and localization. Perception, 21, 765-777.

Green, M. (2000). 'How long does it take to stop?' Analysis of brake reaction times," Transportation Human Factors, 2, 195-216.

Green, M. (2001). The psychology of warnings. Occupational Health and Safety Canada, 3038.

Hakamies-Blomqvist, L., Raitanen, T., \& O'Neill, D. (2002). Driver ageing does not cause higher accident rates per km., Transportation Research Part F: Traffic Psychology and Behaviour, 5, 271-274.

Haigh, R. (1993).The aging process: A challenge for design. Applied Ergonomics, 24,1, 9- 14.

Hess, R.F., Dakin, S.C., Kapoor, N., \& Tewfik, M. (2000). Contour interaction in fovea and periphery. Journal of the Optical Society of America A., 17, 1516-1524.

Kimura, D. (1999). Sex and Cognition, Cambridge, Mass: A Bradford Book, MIT Press.

Klatzky, R.L., Looms, J.M., Golledge \& Cincinelli, R.G. (1990). Acquisition for route and souevay knowledge in the absence of vision. Journal of motor behavior 22, 1, 19- 43.

Lavie, N., Driver, J. (1996). On the spatial extent of attention in object-based visual selection. Perceptual Psychophysics, 58, 1238-1251.

Levi, D.M., Klein, S.A., \& Carney, T. (2000). Unmasking the mechanisms for Vernier acuity: Evidence for a template model of Vernier acuity. Vision Research, 40, 951-972

Levi, D.M., Hariharan, S., \& Klein, S.A. (2002). Suppressive and facilitator spatial interactions in peripheral vision: Peripheral crowding is neither size invariant nor simple contrast masking. Journal of Vision, 2, 2, 167-177, retrieved online at http://journalofvision.org/2/2/3/.

Linn, M., \& Petersen, A. (1985). Emergence and characterization of sex differences in spatial ability: A meta-analysis. Child Development, 56, 1479-1498.

Loke, W.H., \& Song S. (1991). Central and peripheral visual processing in hearing and 
nonhearing individuals. Bull Psychonom Soc, 29:437-440.

Loomis, J.M., Klatzky, R.L., Philbeck, W., \& Golledge, R.G. (1998). Assessing auditory distance perception using perceptually directed action. Perception and Psychophysics, 60, 6, 966-980.

Manton, K.G. (1989). Epidemiological demographic, and social correlates of disability among the eldery. The Milbank Quarterly, 67 (Suppl. 2), Pt. 1, 13-58.

Murray-Leslie, C., (1991). Driving for the person disabled by arthritis. Journal of Rheumatology, 30, 54- 55.

Pirkl J.J., \& Babic, A.L. (1988). Guidelines and Strategies for Designing Transgenerational Products: An Instructor's Manual. Centre for Instructional Development, Syracuse University, Syracuse.

Pylyshyn, Z.W. (1998). Visual indexes in spatial vision and imagery. In R. D. Wright (Ed.), Visual Attention, New York: Oxford University Press, 215-231.

Pylyshyn, Z.W., \& Cohen, J. (1999). Imagined extrapolation of uniform motion is not continuous. Paper presented at the Annual Conference of the Association for Research in Vision and Ophthalmology, Ft. Lauderdale, FL.
Pylyshyn, Z.W. (2000). Situating vision in the world, Trends in Cognitive Sciences, 4, 5, 197-207.

Pylyshyn, Z.W. (2001a). Connecting vision and the world: Tracking the missing link. In $\mathrm{J}$. Branquinho (Ed.), The Foundations of Cognitive Science. Oxford, UK: Claredon Press.

Schuhfried, G. (1992). Wienna Test System, GmB Austria.

Shute, R.H. and Woodhouse, J.G. (1990) Visual fitness to drive after stroke or head injury. Ophthalmic and Physiological Optics . 10, 327-332.

Siegel, M., Kording, P.K., \& Kording, P. (2000). Integrating Top-Down and Bottom-Up Sensory Processing by Somato-Dendritic Interactions. Journal of Computational Neuroscience, 8, 161-173.

Smith, E., Fredrickson, B., Loftus, G. R., \& NoelenHoeksema, S., (2004). Introduction to Psychology, Bucureşti: Ed. Tehnică.

Stins, J.F., \& van Leeuwen, C. (1993). Context influence on the perception of figures as conditional upon perceptual organization strategies. Percept. Psychophysics. 53, 3442.

Wang, Q., Cavanagh, P., \& Green, M. (1994). Familiarity and pop-out in visual search. Perception \& Psychophysics, 56, 495-500.

\begin{tabular}{|c|}
\hline 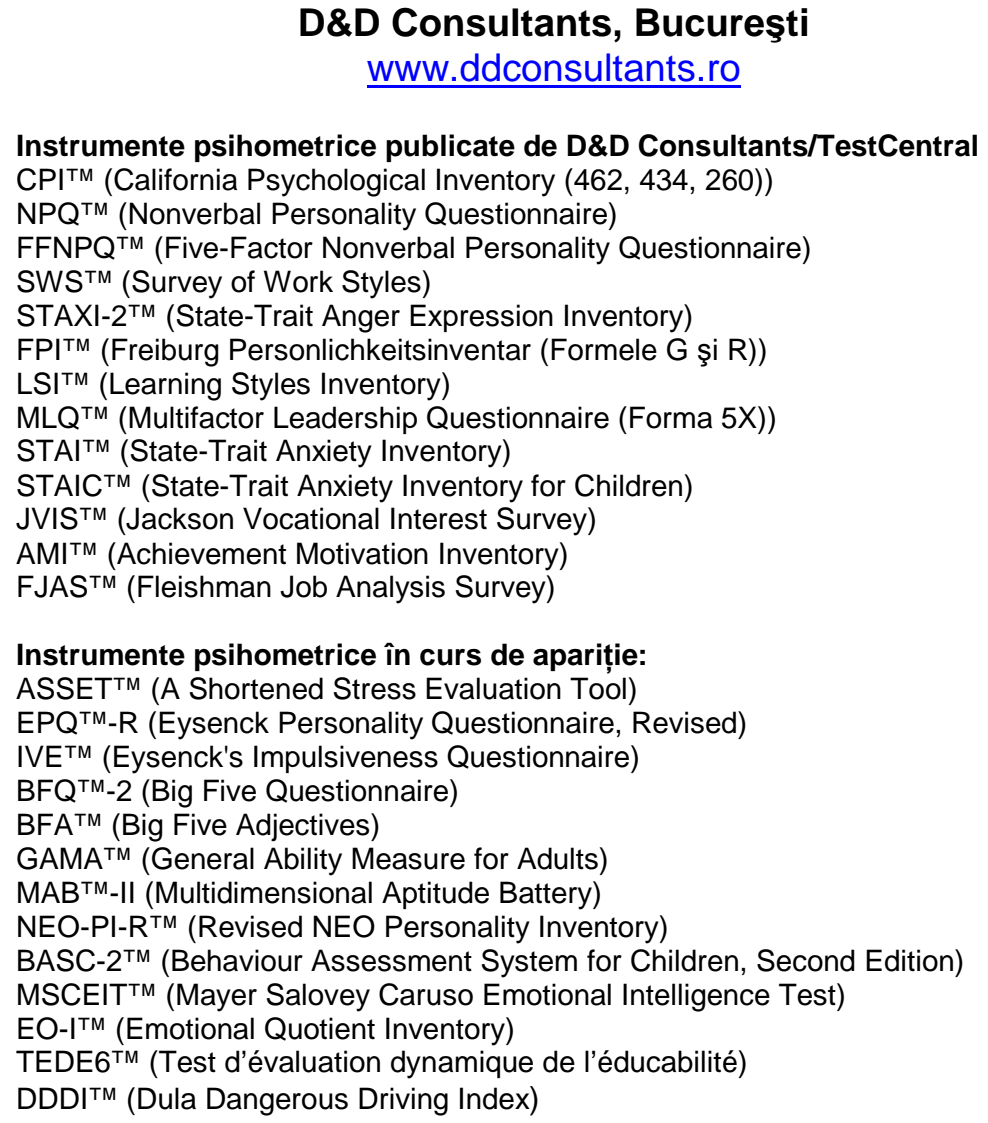 \\
\hline
\end{tabular}

